Original Article

\title{
Effects of strength training program on hip extensors and knee extensors strength of lower limb in children with spastic diplegic cerebral palsy
}

\author{
Thanda Aye ${ }^{1,3)^{*}, \text { Soe Thein }}{ }^{2)}$, Thaingi Hlaing ${ }^{1)}$ \\ 1) Department of Physiotherapy, University of Medical Technology, Yangon, The Republic of the Union \\ of Myanmar \\ 2) National Rehabilitation Hospital, The Republic of the Union of Myanmar \\ 3) Graduate School of Health and Welfare Sciences, International University of Health and Welfare: \\ Ohtawara, Tochigi, Japan
}

\begin{abstract}
Purpose] The purpose of this study was to determine whether strength training programs for hip extensors and knee extensors improve gross motor function of children with cerebral palsy in Myanmar. [Subjects and Methods] Forty children ( 25 boys and 15 girls, mean age: $6.07 \pm 2.74$ years) from National Rehabilitation Hospital, Yangon, Myanmar, who had been diagnosed with spastic diplegic cerebral palsy, Gross Motor Classification System I and II participated in a 6-week strength training program (45 minutes per day, 3 days per week) on hip and knee extensors. Assessment was made, before and after intervention, of the amount of training weight in pounds, as well as Gross Motor Function Measure (GMFM) dimensions D (standing) and E (walking, running, jumping). [Results] All scores had increased significantly after the strength-training program. [Conclusion] A simple method of strength-training program for hip and knee extensors might lead to improved muscle strength and gross motor function in children with spastic diplegic cerebral palsy.

Key words: Cerebral palsy, Strength training, Hip and knee extensors
\end{abstract}

(This article was submitted Oct. 21, 2015, and was accepted Nov. 19, 2015)

\section{INTRODUCTION}

Cerebral Palsy (CP) is a disorder of movement and posture that appears during infancy or early childhood. It is caused by non-progressive damage to the developing brain before, during, or shortly after birth. Spastic CP is the most common form of CP (accounting for approximately $70-80 \%$ of cases of CP) and $50 \%$ of children with spastic CP have diplegia. In spastic diplegic $\mathrm{CP}$, the lower extremities are severely affected but the upper extremities are only mildly impaired, intelligence is usually normal, and epilepsy is not common ${ }^{1)}$. Children with CP have neurodevelopmental disorders, such as spasticity, contracture, reduced coordination, selective voluntary control, and muscle weakness ${ }^{2}$. Among these, muscle weakness is a major motor problem for children with $\mathrm{CP}^{3-9)}$. Muscle weakness is more pronounced distally and the hip extensors, knee extensors, and ankle dorsiflexors are relatively weaker than their antagonists ${ }^{3,7}$.

Muscle strength and resistance training programs have been used as therapeutic interventions to increase muscle strength and to improve muscle function ${ }^{3-13)}$. All clinical trials suggest that muscle strength-training programs can increase muscle strength and may improve motor activity without adverse effects in people with $\mathrm{CP}^{10,11)}$.

The purpose of this study was to determine whether strength-training programs for hip extensors and knee extensors improve gross motor function of Myanmar children with CP.

\footnotetext{
*Corresponding author. Thanda Aye (E-mail: 15s3027@g.iuhw.ac.jp)

(C)2016 The Society of Physical Therapy Science. Published by IPEC Inc.

This is an open-access article distributed under the terms of the Creative Commons Attribution Non-Commercial No Derivatives (by-nc-nd) License $<$ http://creativecommons.org/licenses/by-nc-nd/4.0/>.
} 
Table 1. Description of GMFCS levels in general for all age bands

\begin{tabular}{ll}
\hline Level & Ability \\
\hline Level I & Walks without restrictions \\
Level II & Walks without assistive devices but limitations in community \\
Level III & Walks with assistive devices \\
Level IV & Transported or uses powered mobility \\
Level V & Severely limited dependent on wheelchair \\
\hline
\end{tabular}

Table 2. GMFM

\begin{tabular}{lcc}
\hline Dimension & Items & Maximum scores \\
\hline A. Lying and Rolling & 17 & 51 \\
B. Sitting & 20 & 60 \\
C. Crawling and Kneeling & 14 & 42 \\
D. Standing & 13 & 39 \\
E. Walking, Running and Jumping & 24 & 72 \\
Total & 88 & 264 \\
\hline
\end{tabular}

\section{SUBJECTS AND METHODS}

Forty children ( 25 boys and 15 girls) diagnosed with spastic diplegic CP, were recruited for this study. The children were both inpatients \& outpatients coming for rehabilitation to the National Rehabilitation Hospital (NRH), Yangon, Myanmar. The inclusion criteria were: ages between 4 and 12 years (mean age: $6.07 \pm 2.74$ years); GMFCS levels I and II, with the muscle tone of hip and knee extensors lower than grade +1 of the Modified Ashworth Scale (MAS) and the ability to follow verbal commands. Children were excluded if they: (i) had received a nerve block injection or orthopedic surgery; (ii) had hip and/or knee flexion contracture greater than 10 degrees; or (iii) had unstable seizures and other medical conditions. The data collection procedure is shown in Fig. 1. This study was approved by the Human Research Ethics committee of the University of Medical Technology, Yangon (UMTY), Myanmar. All subjects and parents/caregivers received explanations regarding the purpose and procedures of the study before voluntarily agreeing to participate. All parents/caregivers were required to give written informed consent for participation before the start of the study procedures, and were reminded that they had the right to withdraw from the study at any time. All subjects in the study were able to continue their usual therapy at the NRH.

The study design was one group pretest-posttest design. All forty children in this study were categorized into GMFCS levels I and II according to the original version of GMFCS. The GMFCS is based on gross motor development of self-initiated movement, and consists of a five-level classification system (Table 1) with descriptions of four age bands: before the 2nd birthday; between the 2nd and 4th birthdays; between the 4th and 6th birthdays; and between the 6th and 12th birthdays ${ }^{14)}$. The original version of GMFCS used in the present study was in effect prior to the 2007 Expended and Revised version (GMFCS-E \& R) with descriptions on five age bands (younger than 2, 2-4, 4-6, 6-12 and 12-18 years) ${ }^{15}$. Children at level I and level II learn to walk without aids, children at level III walk with aids, children at level IV rely mainly on wheelchair mobility and children at level V have no means of independent mobility ${ }^{14}{ }^{15}$ ). One study also confirmed the reliability and validity of the GMFCS, supporting its use in clinical practice and research ${ }^{16)}$.

Muscle strength can be defined as the ability of skeletal muscle to develop force for providing stability and mobility within the musculoskeletal system, so that functional movement can take place ${ }^{17}$. Muscle strength training can be defined as "methods to increase one's ability to exert or resist force"18). Several types of resistance can be used for strength training ${ }^{19)}$. The free weights (adjustable weight cuffs with sand bags and Velcro straps) were used as resistance in this study.

The GMFM is a standardized observational instrument designed and validated to measure change in gross motor function over time in children with CP. GMFM is a criterion-based observational measure with 88 items that assesses motor function in five dimensions. The five dimensions and their respective items and maximum scores are shown in Table 2. Each item is assessed and scored on four-point ordinal scale: $0=$ cannot initiate activity, $1=$ initiates activity, $2=$ partially completes activity and $3=$ completes activity ${ }^{20,21)}$. Dimension D (13 items to measure motor function in standing, scoring from 0 to 39 ) and dimension E ( 24 items to measure motor function in walking, running and jumping, scoring from 0 to 72 ) were used as the outcome measures for this study.

The amount of training weight in pounds, which was maximum amount of weight that the child could lift in one time, GMFM dimension D and E were assessed at baseline before the start of training program and after the completion of six weeks training program. All forty subjects were given strength-training program, which included progressive resistance hip 

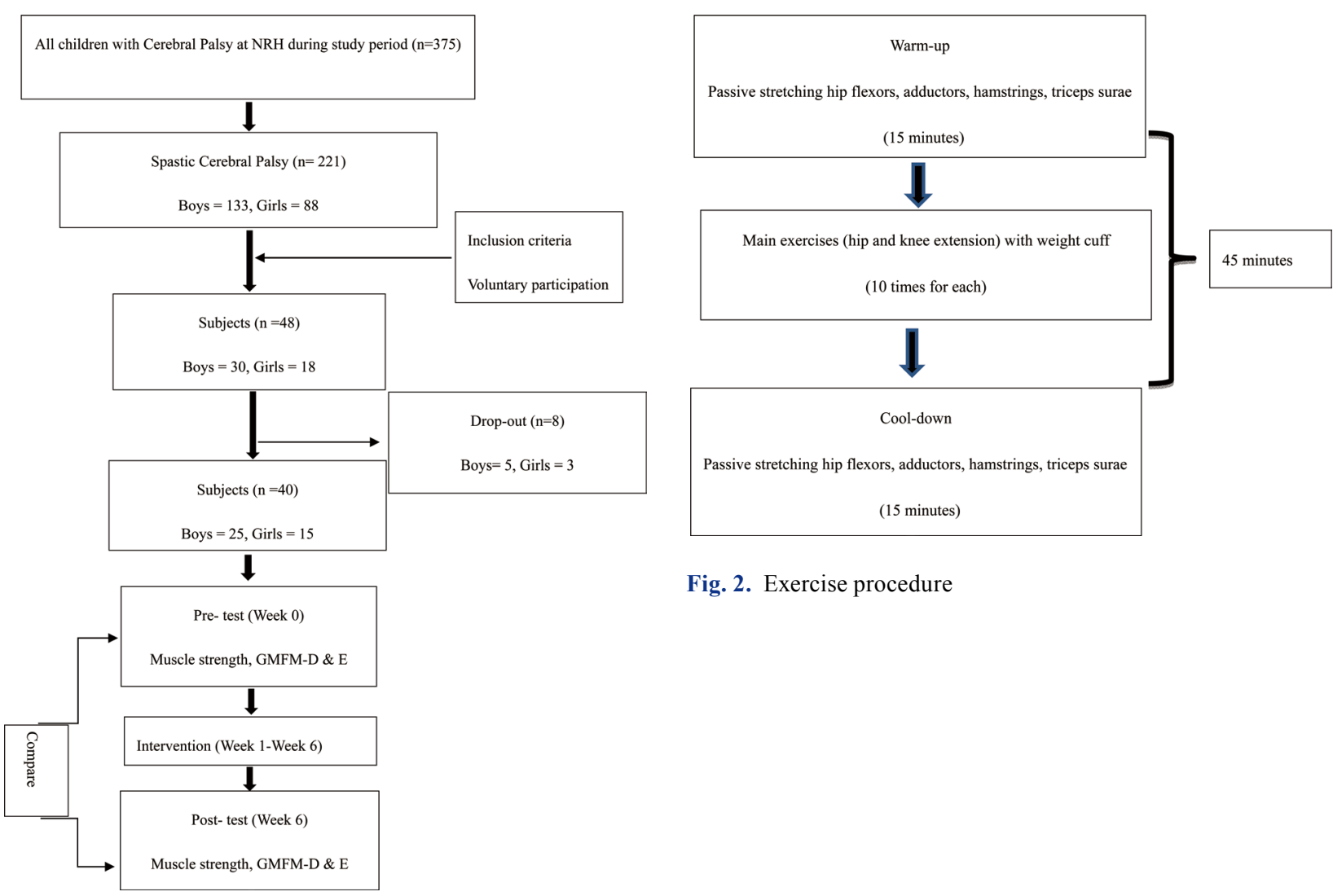

Fig. 2. Exercise procedure

Fig. 1. Flow diagram of the study

and knee extension one session (45 minutes) per day, three times a week for total six weeks. The intervention procedure involved passive stretching of hip flexors, adductors, hamstrings, triceps surae for 15 minutes as warm-up. The main exercise, extension exercise for both hip and knee extensors with weight cuff, was done ten times for each muscle group on each side for 30 minutes. For hip extensors, the subject was lying prone, the weight cuff was placed just above knee joint and the subject was asked to lift the thigh with weight to full extension. The subject was lying supine with knees slightly bent, a foam roll or a pillow was placed under knees, the weight cuff was placed just above ankle joint and the subject was asked to lift the lower leg with weight to full extension for knee extensors. The intervention procedure was finished with passive stretching of hip flexors, adductors, hamstrings, triceps surae for 15 minutes as cool-down. The intervention procedure is shown in Fig. 2. The strength-training program was performed 10 repetitions for each muscle group on each side, one session per day for three days per week up to 6 consecutive weeks. A daily diary of physical activity of each subject was kept by the parents or caregivers during the study period. After 6 consecutive weeks training program, the subject was discharged. The parents or caregivers of each subject were requested to ask the subject to perform the same main exercise program at home by the guidance of a written home exercise program. All subjects were requested to visit the study area at once per every 2 weeks up to 6 weeks (three times) as follow up. This study was firstly proposed to assess all outcome measures at the end of 6 weeks training and at the end of 6 weeks follow up (total 12 weeks) but there were only 7 subjects who were able to come all three times of follow up. More than $75 \%$ of the subjects were not able to completely come all three times of follow up because most of the subjects in this study were from suburbs of Yangon and other rural areas of Myanmar. The subjects who were absent from regular treatment of 3 days for total 6 consecutive weeks were taken as drop-out.

Descriptive statistics [mean, median and standard deviation (SD)] were calculated using independent t-test.

Data were analyzed and processed scientifically using STATISTICA software version 5.5. A p value less than 0.05 was considered statistically significant.

\section{RESULTS}

The outcome measures only at the end of 6 consecutive weeks were calculated as final data. The general characteristics of the subjects are presented in Table 3. The mean values and standard deviations (SD) of pre-test and post-test outcome measures and $p$ values of the participants are presented in Table 4. Statistically significant changes were seen in the amount of training weight in pounds and GMFM-D and E. 
Table 3. General characteristics of subjects

\begin{tabular}{lcc}
\hline Characteristics & Mean (SD) & Frequency $(\%)$ \\
\hline Age, 4-12 years years & $6.07(2.74)$ & $40(100)$ \\
4-6 years & & $23(57.5)$ \\
6-12 years & $17(42.5)$ \\
Gender & \\
Boys & $25(62.0)$ \\
Girls & $15(38.0)$ \\
GMFCS & \\
Level I & $30(75)$ \\
Level II & $10(25)$ \\
\hline
\end{tabular}

Table 4. Results of strength training

\begin{tabular}{lcc}
\hline & Pre-test (Mean \pm SD) & Post-test (Mean \pm SD) \\
\hline Training weight (lb) & & \\
Hip extensors (Right) & $1.81 \pm 1.51$ & $3.50 \pm 2.16^{*}$ \\
Hip extensors (Left) & $1.74 \pm 1.20$ & $3.09 \pm 1.80^{*}$ \\
Knee extensors (Right) & $1.86 \pm 1.49$ & $3.57 \pm 2.1^{*}$ \\
Knee extensors (Left) & $1.77 \pm 1.23$ & $3.23 \pm 1.75^{*}$ \\
GMFM & & \\
GMFM-D & $28.4 \pm 11.1$ & $33.2 \pm 11.1^{*}$ \\
GMFM-E & $42.4 \pm 19.3$ & $54.9 \pm 22.5^{*}$ \\
\hline$* \mathrm{p}<0.05$ & &
\end{tabular}

\section{DISCUSSION}

The purpose of this study was to determine whether strength-training program on hip extensors and knee extensors improves gross motor function of children with spastic diplegic CP (GMFCS level I \& II) in Myanmar. The results of this study supported the effectiveness of prescribing strength-training program on hip and knee extensor muscle groups of lower limbs in patients with spastic diplegic CP as a method to enhance their functional abilities and to increase their gross motor function. After 6 consecutive weeks of strength-training program, the subjects were found to achieve increased mean values of maximum weight for training for all muscle groups and GMFM dimension D and E. Many studies reported that muscle strength and gross motor function activities significantly improved after strength-training program. Domiano et al. reported that children with spastic diplegia increased quadriceps femoris muscle strength through heavy resistance exercise, three times per week for 6 weeks using ankle weights at load of approximately $65 \%$ of each child's maximum isotonic force production $^{3,4)}$. MacPhail \& Kramer stated that there was a direct relationship between knee extensor strength and gross motor ability, which meant improvement in muscular strength, was associated with improvement in walking efficiency and functional abilities in adolescents with $\mathrm{CP}^{5,6}$. In the study of Functional outcomes of strength training in spastic cerebral palsy by Domiano and Abel, the results of their study reinforced the relationship of strength to motor function in children with $\mathrm{CP}$ and further demonstrated the effectiveness of strengthening in this population ${ }^{8)}$. In the randomized clinical trial of strength training in young people with cerebral palsy by Dodd et al., home-based, 6 weeks strength training program on knee extensors and ankle plantar flexors was effective in increasing muscle strength and GMFM-D and E of young people (mean age 13 years 1 month, SD 3years 1 month: range 8 to 18 years) with spastic diplegic CP (GMFCS level I to III) $)^{9)}$. Dodd et al. also reported that strength training programs could increase strength and may improve motor activity in people with $\mathrm{CP}$ without adverse effects in their study of a systematic review of the effectiveness of strength training programs for people with $\mathrm{CP}^{10)}$. A pilot study using repeated measure design of the effects of progressive resistance training for children with $\mathrm{CP}$ by Morton et al. also found that muscle strength and GMFM dimension D and E increased immediately after 6 weeks training program using free weights ${ }^{11}$.

In this study, all subjects exhibited increased muscle strength (increased amount of training weight in pounds) and GMFM dimension $\mathrm{D}$ and $\mathrm{E}$ from baseline to the certain extent until the end of 6 weeks strength training program. Although this study was first proposed to assess the outcomes measures at the end of 6 weeks training and at the end of 6 weeks follow up (total 12 weeks) but there were only 7 subjects who were able to come all three times of follow up and the result of those 7 subjects were not calculated in the results. The results of the present study supported the effectiveness of prescribing strength 
training program on muscles of lower limbs in patients with spastic diplegic CP as a method to enhance their functional abilities and to increase their gross motor function. The current physical therapy program including strength training program was as effective as the previous studies, but with much shorter time and utilized unsophisticated and inexpensive equipment which was available in the most of the Physiotherapy Departments in our country. Therefore, the adoption of this regime into clinical practice was feasible. The limitations of this study were absence of control group, not using standardized assessment of muscle strength, not using GMFM-66 with gross motor ability estimator (GMAE) software, not involving other physiologic types of $\mathrm{CP}$ and presence of weakness that the subjects were able to take usual therapies from the NRH that might have influenced the outcome measures. In conclusion, the results of this study suggested that a simple method of strength training program might lead to improve muscle strength and gross motor function in children with spastic diplegic CP. This simple methodology could provide powerful motivation to these patients group to encourage more active lifestyle and allow increased activity and participation within family and community settings.

\section{ACKNOWLEDGEMENTS}

We would like to express our sincere thanks to all subjects and their families for their willing participation and co-operation in this study, to the teachers and colleagues from UMTY and NRH, Yangon for their friendliness, understanding and sharing their knowledge throughout the study and we wish to extend the heartfelt gratitude and deep respect to Professor Hitoshi Maruyama for helping the preparation of this manuscript.

\section{REFERENCES}

1) Berker N, Yalcin S: The help guide to cerebral palsy, 1st ed. Avrupa Medical Bookshop Co. Ltd. \& Global-HELP Organization, 2004, p 5-11.

2) Gormley ME Jr: Treatment of neuromuscular and musculoskeletal problems in cerebral palsy. Pediatr Rehabil, 2001, 4: 5-16. [Medline]

3) Damiano DL, Kelly LE, Vaughn CL: Effects of quadriceps femoris muscle strengthening on crouch gait in children with spastic diplegia. Phys Ther, 1995, 75: 658-667, discussion 668-671. [Medline]

4) Damiano DL, Vaughan CL, Abel MF: Muscle response to heavy resistance exercise in children with spastic cerebral palsy. Dev Med Child Neurol, 1995, 37: 731-739. [Medline] [CrossRef]

5) McPhail HE, Kramer JF: Relationships among measures of walking efficiency, gross motor ability, and isokinetic strength in adloscents with cerebral palsy. Pediatr Phys Ther, 1994, 6: 3-8.

6) MacPhail HE, Kramer JF: Effect of isokinetic strength-training on functional ability and walking efficiency in adolescents with cerebral palsy. Dev Med Child Neurol, 1995, 37: 763-775. [Medline] [CrossRef]

7) Wiley ME, Damiano DL: Lower-extremity strength profiles in spastic cerebral palsy. Dev Med Child Neurol, 1998, 40: 100-107. [Medline] [CrossRef]

8) Damiano DL, Abel MF: Functional outcomes of strength training in spastic cerebral palsy. Arch Phys Med Rehabil, 1998, 79: 119-125. [Medline] [CrossRef]

9) Dodd KJ, Taylor NF, Graham HK: A randomized clinical trial of strength training in young people with cerebral palsy. Dev Med Child Neurol, 2003, 45: 652-657. [Medline] [CrossRef]

10) Dodd KJ, Taylor NF, Damiano DL: A systematic review of the effectiveness of strength-training programs for people with cerebral palsy. Arch Phys Med Rehabil, 2002, 83: 1157-1164. [Medline] [CrossRef]

11) Morton JF, Brownlee M, McFadyen AK: The effects of progressive resistance training for children with cerebral palsy. Clin Rehabil, 2005, 19: 283-289. [Medline] [CrossRef]

12) Jung JW, Her JG, Ko J: Effect of strength training of ankle plantarflexors on selective voluntary motor control, gait parameters, and gross motor function of children with cerebral palsy. J Phys Ther Sci, 2013, 25: 1259-1263. [Medline] [CrossRef]

13) Kim JH, Seo HJ: Effects of trunk-hip strengthening on standing in children with spastic diplegia: a comparative pilot study. J Phys Ther Sci, 2015, 27: 1337-1340. [Medline] [CrossRef]

14) Palisano R, Rosenbaum $P$, Walter $S$, et al.: Development and reliability of a system to classify gross motor function in children with cerebral palsy. Dev Med Child Neurol, 1997, 39: 214-223. [Medline] [CrossRef]

15) Palisano RJ, Rosenbaum P, Bartlett D, et al.: Content validity of the expanded and revised Gross Motor Function Classification System. Dev Med Child Neurol, 2008, 50: 744-750. [Medline] [CrossRef] 
16) Ko J, Woo JH, Her JG: The reliability and concurrent validity of the GMFCS for children with cerebral palsy. J Phys Ther Sci, 2011, 23: 255-258. [CrossRef]

17) Harris BA, Watkins MP: Muscle performance: principles and general theory. In: Harms- Ringdahl K (ed.), Muscle Strength. Edinburgh: Churchill Livingstone 1993, p 5.

18) Bernhardt DT, Gomez J, Johnson MD, et al. Committee on Sports Medicine and Fitness: Strength training by children and adolescents. Pediatrics, 2001, 107: 1470-1472. [Medline] [CrossRef]

19) Gardiner MD: Active movement. In: The principle of exercise therapy, 4th ed. 1885, p 52.

20) Russell DJ, Rosenbaum PL, Gowland C, et al.: Gross Motor Function Measure Manual, 2nd ed. Hamilton, Ontario: McMaster University, 1993.

21) Russell DJ, Rosenbaum PL, Avery LM, et al.: Gross Motor Function Measure (GMFM-66 \& GMFM-88) user's manual. London: MacKeith Press, 2002. 